\title{
A Comparative Characterization of the HPA-MCM-48 Type Catalysts Produced by the Direct Hydrothermal and Room Temperature Synthesis Methods
}

\author{
Y. Gucbilmez, ${ }^{1}$ A. S. Yargic, ${ }^{2}$ and I. Calis ${ }^{1}$ \\ ${ }^{1}$ Department of Chemical Engineering, Anadolu University, Iki Eylul Campus 26555 Eskisehir, Turkey \\ ${ }^{2}$ Department of Chemical and Process Engineering, Bilecik University, 11210 Bilecik, Turkey \\ Correspondence should be addressed to Y. Gucbilmez, ygucbilmez@anadolu.edu.tr
}

Received 14 October 2011; Revised 26 December 2011; Accepted 27 December 2011

Academic Editor: Shuangxi Xing

Copyright () 2012 Y. Gucbilmez et al. This is an open access article distributed under the Creative Commons Attribution License, which permits unrestricted use, distribution, and reproduction in any medium, provided the original work is properly cited.

\begin{abstract}
MCM-48 type support materials synthesized by the direct hydrothermal synthesis (HTS) and room temperature synthesis (RTS) methods were incorporated with tungstophosphoric acid (TPA) in the range of $10-40 \mathrm{wt} \%$ by using a wet impregnation technique in methanol solutions. Resulting HPA-MCM-48 catalysts were characterized by the XRD, Nitrogen Physisorption, SEM, TEM, EDS, and FT-IR methods in order to determine the effects of different initial synthesis conditions on the catalyst properties. RTS samples were found to have better crystalline structures, higher BET surface areas, and higher BJH pore volumes than HTS samples. They also had slightly higher TPA incorporation, except for the $40 \mathrm{wt} \%$ samples, as evidenced by the EDS results. Keggin ion structure was preserved, for both methods, even at the highest acid loading of $40 \mathrm{wt} \%$. It was concluded that the simpler and more economical RTS method was more successful than the HTS method for heteropoly acid incorporation into MCM-48 type materials.
\end{abstract}

\section{Introduction}

MCM-48 type materials with cubic pore geometries were first synthesized by the Mobil researchers in the year 1992 as a member of the new family of mesoporous materials named as the M41S family $[1,2]$. Owing to high BET surface areas (up to $1600 \mathrm{~m}^{2} / \mathrm{g}$ ), high pore volumes (up to $1.2 \mathrm{~cm}^{3} / \mathrm{g}$ ), and narrow pore size distributions in the mesoporous region [35 ], they have been the subject of many different studies ever since $[4-10]$.

Heteropoly acids (HPAs) are complex proton acids that incorporate polyoxometalate anions (heteropoly anions) having metal-oxygen octahedra as the basic structural units. HPAs have several advantages such as very strong Bronsted acidities approaching the super acid region and high oxidant activities in multielectron redox reactions under mild conditions. Their acid-base and redox properties can be varied widely by changing their chemical compositions. Solid HPAs have a discrete ionic structure, containing the fairly mobile heteropoly anions and counter-cations $\left(\mathrm{H}^{+}, \mathrm{H}_{3} \mathrm{O}^{+}\right.$,
$\mathrm{H}_{5} \mathrm{O}_{2}{ }^{+}$, etc.). This unique structure results in significantly high proton mobility and a pseudo liquid phase behaviour. In addition, HPAs are highly soluble in polar solvents and their thermal stabilities are quite high. These properties make HPAs potentially promising acid, redox, and bifunctional catalysts in both homogeneous and heterogeneous systems $[11,12]$. Despite their advantageous properties, HPAs have very low BET surface areas $\left(<10 \mathrm{~m}^{2} / \mathrm{g}\right)$ in the solid phase; they are essentially nonporous materials with a few acid sites present on their external surfaces for reactions with different molecules such as hydrocarbons $[13,14]$. This problem may be overcome by incorporating HPAs on high surface area supports like silica, zeolites, or mesoporous materials. Among these supports, mesoporous materials including MCM-48 are quite attractive since they have large BET surface areas, larger pore diameters compared to zeolites, and regular crystalline structures contrary to silica which is amorphous. In fact, in literature, there are several studies involving the synthesis, characterization, and applications of HPA-MCM-48 type catalysts [9, 15-19]. 
In this study, a direct Hydrothermal Synthesis method (HTS) and a Room Temperature Synthesis method (RTS) were used to produce the purely siliceous MCM- 48 support materials. The methods taken from the literature were modified by the authors by making some changes in the gelation, drying, and calcination steps in order to enhance the physical properties such as the BET surface area, the portion of open pores, and the total pore volume. The as-synthesized materials were impregnated with tungstophosphoric acid (TPA) in the range of $10-40 \mathrm{wt} \%$ by using a wet-impregnation technique in methanol solutions. The physical and chemical properties of the resulting catalysts were obtained by the XRD, Nitrogen Physisorption, SEM, TEM, EDS, and FTIR methods, and the results were compared in order to determine which initial method was more successful for the incorporation HPAs into MCM-48 type materials. To our knowledge, no such comparative work exists in literature for HPA-MCM-48 type catalysts [9, 15-19]; hence the results were presented as original findings.

\section{Experimental}

2.1. Materials. Tetraethyl orthosilicate (TEOS, from Merck, 98\%) was used as the silica source, cetyltrimethylammonium bromide (CTMABr, from Merck) as the surfactant, distilled water as the solvent, and $\mathrm{NaOH}$ (in the form of pellets, from Riedel-de Haen), ammonia (ammonium hydroxide solution, $26 \%$, from Riedel de Haen), and ethanol (technical grade, Merck) as the mineralizing agents for the syntheses of the purely siliceous MCM-48 materials. Tungstophosphoric acid (Phosphotungstic acid hydrate from Fluka) was used as the HPA source and methanol (from Baker) as the solvent for HPA incorporation into the MCM-48 support materials.

2.2. Synthesis of the HPA-MCM-48 Catalysts. The first purely siliceous MCM-48 catalyst, produced by using a direct hydrothermal synthesis method (HTS), was labelled as MCM-48-HTS. The molar composition of the reaction gel and the aging time were taken from a previous study [6] and the rest of the recipe was developed by the authors as follows: 21 grams of CTMABr was dissolved in $143 \mathrm{~mL}$ distilled water with vigorous stirring $(600 \mathrm{rpm})$ at $30^{\circ} \mathrm{C}$ in order to obtain a clear surfactant solution. After the surfactant solution was formed, sufficient amount of $\mathrm{NaOH}$ (in the form of pellets) was added slowly to act as the mineralizing agent for the mineralization of the silica source into soluble species capable of interacting with the surfactant molecules in the later reaction steps [21]. Then, the silica source, TEOS, was added dropwise under vigorous stirring at $30^{\circ} \mathrm{C}$ to form the synthesis mixture. It was important to add TEOS slowly in order to enhance its interactions with the mineralizing agent and the surfactant molecules. In addition, vigorous stirring was preferred to enhance the solubilities of the silica source and the surfactant molecules and to force the gelation/synthesis reaction to completion. The formation of a gel, with the molar composition of $1.0 \mathrm{TEOS} / 0.48 \mathrm{NaOH} / 0.4 \mathrm{CTMABr} / 4.55 \mathrm{H}_{2} \mathrm{O}$, was observed after the addition of the silica source and the gel was further mixed for an additional hour to obtain a homogeneous medium. The homogenous gel was transferred into a Teflon bottle and the bottle was well sealed to prevent any composition change during the crystallization/aging stage. The Teflon bottle was inserted into an oven preheated to $393 \mathrm{~K}$ where it was kept for 3 days. A long aging period and a high aging temperature were preferred in order to increase the crystallinity and the pore size of the product [22]. The aging/crystallization period was followed by the washing stage. In literature, in most of the studies [4-9], no detailed information is given concerning the washing stage of the MCM-48 synthesis. However, it is known that any excess surfactant or other basic material accompanying the MCM48 precursor will be removed through a careful washing procedure increasing the calcination efficiency [23], pore volume, and BET surface area. Hence, in this work, the washing stage was continued until neutral $\mathrm{pH}$ values; that is, the slurry obtained from the oven was filtered and washed in a vacuum system until the $\mathrm{pH}$ of the filtrate became 7.0. The washed sample was dried at ambient temperature for 24 hours. Ambient drying was preferred over fast (vacuum) drying in an oven since it is known that slower rate of drying increases the portion of the open pores (pores interconnected in a network) in the structure with respect to the closed pores (isolated/single pores) and facilitates the removal of the templates from the structure for the M41S family of materials [22]. Finally, the dried sample was calcined in a quartz tube of $1.25 \mathrm{~cm}$ inner diameter and $120 \mathrm{~cm}$ length designed by the authors, which had a membrane in the middle for the passage of dry air and the fixation of the sample and which allowed the dry air to pass through the whole sample rather than only certain zones. The sample was heated from ambient temperature to $823 \mathrm{~K}$ with a heating rate of $1^{\circ} \mathrm{C} / \mathrm{min}$ and kept at this temperature for 6 more hours under constant flow of dry air. It is known that the crystallinity of the product increases as the heating rate (calcination rate) decreases or the calcination duration increases [24]. Hence a low heating rate $\left(1^{\circ} \mathrm{C} / \mathrm{min}\right)$ was employed and a long total calcination time of 15 hours was achieved. The calcination temperature was chosen as $823 \mathrm{~K}$ since it was commonly employed in literature $[5-7,9]$ and was shown to be the optimum calcination temperature for MCM-41 type materials [25] which have very similar properties with MCM-48 type materials except for the pore geometries.

MCM-48-RTS, the MCM-48 type catalyst produced by the room temperature synthesis method, was synthesized using a recipe similar to that given by Schumacher et al. [5] with the abovementioned modifications in the gelation, washing, and calcination steps: 21 grams of CTMABr was dissolved in about $470 \mathrm{~mL}$ distilled water at room temperature to yield a white suspension. 7.83 moles of ethanol was added dropwise under vigorous stirring $(600 \mathrm{rpm})$ and a clear solution was seen to form. Then, the mineralizing agent, ammonia, was also added dropwise, and the new solution was let to mix vigorously for 10 minutes. The required amount of TEOS was also added dropwise under vigorous stirring and a suspension was formed with the molar composition of $1.0 \mathrm{TEOS} / 12.5 \mathrm{NH}_{3} / 54 \mathrm{EtOH} / 0.4 \mathrm{CTMABr} / 174 \mathrm{H}_{2} \mathrm{O}$. After vigorously stirring for 2 hours at room temperature, 
Table 1: Physical Properties of the Purely Siliceous Catalysts.

\begin{tabular}{|c|c|c|c|c|c|c|}
\hline \multirow{2}{*}{ Sample ID } & \multicolumn{6}{|c|}{$2 \theta\left(^{\circ}\right)$} \\
\hline & Primary (211) peak & Secondary peaks & $d_{211}(\mathrm{~nm})$ & $a(\mathrm{~nm})$ & $V_{p}^{*}\left(\mathrm{~cm}^{3} / \mathrm{g}\right)$ & $\delta(\mathrm{nm})$ \\
\hline MCM-48-HTS & 2.60 & $3.88,4.38$ & 3.40 & 8.33 & 0.629 & 1.13 \\
\hline MCM-48-RTS & 2.70 & $4.40,5.06$ & 3.27 & 8.01 & 0.692 & 1.03 \\
\hline
\end{tabular}

* Primary mesopore volume determined by using the $\alpha_{s}$ method and data taken from the adsorption isotherm.

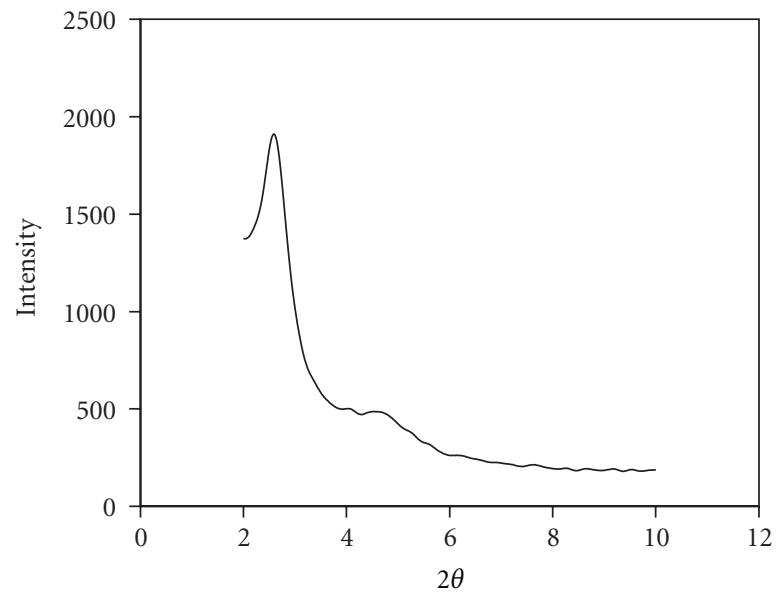

(a)

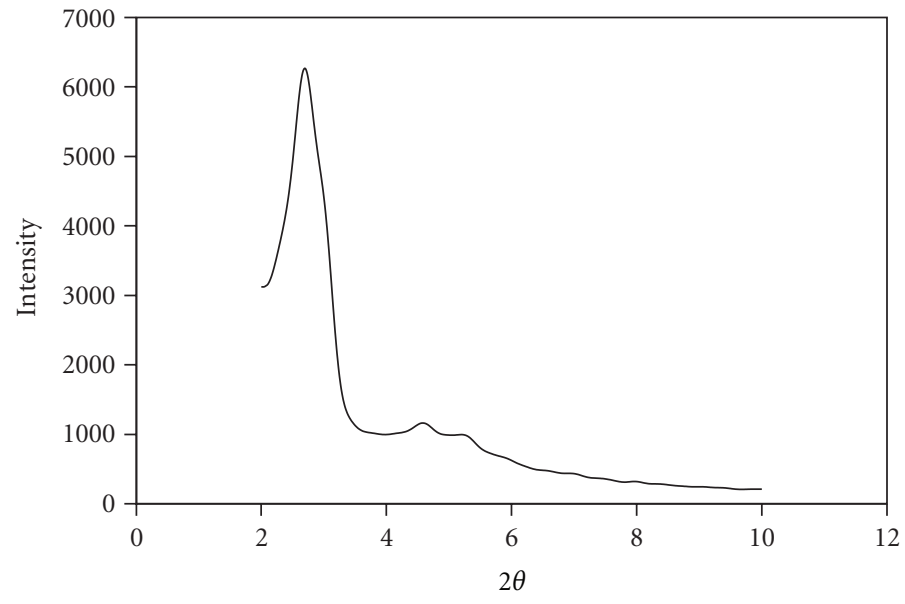

(b)

FIGURE 1: XRD patterns of the purely siliceous catalysts (a) MCM-48-HTS and (b) MCM-48-RTS.

the resulting precipitate was recovered by filtration, washed with distilled water until the $\mathrm{pH}$ of the filtrate became neutral, and dried in air at ambient temperature for 24 hours. The sample was calcined in the quartz tube mentioned previously by following the same procedure as that used for MCM-48-HTS.

Tungstophosphoric acid was incorporated into the assynthesized samples by using a wet-impregnation technique [9] with some modifications. Desired amount of HPA was added slowly into $15 \mathrm{~mL}$ methanol and the solution was mixed at room temperature for 10 minutes. 0.5 gram of as-synthesized MCM-48 was added slowly to this solution under continuous stirring. The resulting mixture was left on the magnetic stirrer for 12 hours under vigorous stirring at room temperature and dried in an oven at $90^{\circ} \mathrm{C}$ long enough to evaporate the methanol. Finally, the solid product was heated at $200^{\circ} \mathrm{C}$ for 8 hours to increase the structural stability.

2.3. Characterization Methods. XRD patterns of the assynthesized samples were obtained using $\mathrm{CuK}_{\alpha}$ radiation $(\lambda=0.15406 \mathrm{~nm})$ on a Rigaku Rint 2000 diffractometer. The spectra were scanned in the range of $2-10^{\circ}$ for the purely siliceous MCM- 48 samples and $2-40^{\circ}$ for the HPA incorporated samples with a step size of 0.02 and a scanning speed of $2(2 \theta / \mathrm{min})$. Nitrogen physisorption isotherms at $77 \mathrm{~K}$ were obtained in a Quantachrome Autosorb 1C instrument. Before the experiments, the purely siliceous samples were outgassed at $300^{\circ} \mathrm{C}$ and the HPA-incorporated samples were outgassed at $200^{\circ} \mathrm{C}$ for $\sim 5 \mathrm{~h}$ in vacuum. The surface area values were evaluated using the BET (Brunauer-EmmetTeller) equation and the pore size distributions and total pore volumes were obtained by applying the BJH (BarretJoyner-Halenda) method to the desorption branch of the isotherms. SEM and EDS results were obtained on the Zeiss Supra 50 VP Microscope with $20 \mathrm{kV}$ accelerating voltage and 7.5-10.5 mm working distance while TEM photographs were taken on JEOL 2100F HRTEM. FT-IR spectra were obtained on a PerkinElmer Spectrum 100 Spectrometer. Pyridine was adsorbed on the catalyst samples before the FT-IR experiments. The samples were outgassed at $120^{\circ} \mathrm{C}$ overnight prior to pyridine adsorption and pyridine adsorption was carried out at room temperature before the FT-IR spectra were taken.

\section{Results and Discussion}

\subsection{XRD Results}

3.1.1. Purely Siliceous Samples. The XRD plots of the purely siliceous samples MCM-48-HTS and MCM-48-RTS are given in Figure 1. It is well known that the MCM-48 type materials yield their XRD patterns in the $2 \theta$ range of $2-$ $10^{\circ}$ with the highest intensity peak appearing around $2.5^{\circ}$ $[26,27]$.

Table 1 summarizes the $2 \theta, d_{211}, a$, and $\delta$ values for the purely siliceous samples. $2 \theta$ values are given for the primary characteristic (211) peak and the secondary characteristic peaks observed. The $d_{211}$ value, which indicates interplanar spacing, is calculated by using the position of the (211) peak 
TABLE 2: Nitrogen physisorption results of the purely siliceous and HPA-incorporated catalysts.

\begin{tabular}{lccccccc}
\hline Sample ID & BET S.A. $\left(\mathrm{m}^{2} / \mathrm{g}\right)$ & $V_{t}\left(\mathrm{~cm}^{3} / \mathrm{g}\right)$ & $d_{p}(\mathrm{~nm})$ & Sample ID & BET S.A. $\left(\mathrm{m}^{2} / \mathrm{g}\right)$ & $V_{t}\left(\mathrm{~cm}^{3} / \mathrm{g}\right)$ & $d_{p}(\mathrm{~nm})$ \\
\hline MCM48-HTS & 1134 & 0.907 & 2.2 & MCM-48-RTS & 1250 & 0.976 & 2.2 \\
HTS-10\% & 898 & 0.626 & 1.7 & RTS-10\% & 1241 & 0.789 & 2.3 \\
HTS-20\% & 702 & 0.599 & 1.7 & RTS-20\% & 1235 & 0.831 \\
HTS-30\% & 402 & 0.290 & 1.8 & RTS-30\% & 953 & 0.660 & 2.2 \\
HTS-40\% & 231 & 0.318 & 1.7 & RTS-40\% & 580 & 0.355 \\
\hline
\end{tabular}

${ }^{*} V_{t}$ (total pore volume) and $d_{p}$ (average pore diameter) values were evaluated by using the BJH method and desorption data.

and Bragg's Law [28-30]. The lattice parameter, $a$, which shows the unit cell size, is calculated using (1) and the pore wall thickness, $\delta$, is calculated using $(2)[28,29]$. In (2),

$$
\begin{gathered}
a=d_{211} \sqrt{ } 6 \\
\delta=\frac{a}{x_{o}}\left[1-\left(\frac{\rho V_{p}}{\left(1+\rho V_{p}\right)}\right)\right]
\end{gathered}
$$

$x_{o}$ is a constant number which can be taken as 3.09 for MCM48 type materials, $V_{p}$ denotes the primary mesopore volume calculated by employing the $\alpha_{s}$ method on the adsorption branch of the nitrogen physisorption isotherms [31, 32], and $\rho$ denotes the pore wall density (solid density) which can be taken as $2.2 \mathrm{~g} / \mathrm{cm}^{3}$ for MCM-48 type materials [28, 29].

Figure 1 and Table 1 depict that the primary characteristic (211) peak expected around $2.5^{\circ}[26,27]$, is obtained for both samples while the secondary characteristic (220) peak expected around $3.0^{\circ}[26,27]$ is not obtained for any of the samples. For the RTS sample, the secondary characteristic (420) and (431) peaks [27], indicating the Ia3d space group symmetry, are formed around 4.40 and $5.06^{\circ}$, respectively. For the HTS sample, on the other hand, the (400) and (420) peaks [27] are formed around 3.88 and $4.38^{\circ}$, respectively, with very low intensities. The primary characteristic (211) peak appears at $2.60^{\circ}$ and $2.70^{\circ}$ for the HTS and RTS samples, respectively. Hence, it is expected that both samples have similar average pore sizes. This finding is verified by the pore size distribution graphs given in Figure 7 and the BJH results given in Table 2. The actual pore diameter of the HTS sample is $2.18 \mathrm{~nm}$ whereas the actual pore diameter of the RTS sample is $2.17 \mathrm{~nm}$, both of which can be rounded to $2.2 \mathrm{~nm}$. Investigation of Figure 1 also shows that the RTS sample has a high intensity (211) peak; however, there is some broadening in this peak indicating inhomogeneity in the mesoporous structure due to some structural degradation and loss of long range order [3335]. In terms of the lattice parameter, $a$, the MCM-48-HTS sample has a somewhat higher value than the MCM-48-RTS sample which indicates that it also has a somewhat larger unit cell compared to the RTS sample.

In the $\alpha_{s}$ method, the amount of nitrogen adsorbed on a nonporous reference adsorbent is expressed as the reduced standard adsorption $\alpha_{s}$, defined as the ratio of the amount adsorbed, at a given relative pressure $P / P$ 。 to the amount adsorbed at the relative pressure $P / P_{\circ}=0.4$. Then, the actual adsorbed volumes of the sample taken from the adsorption isotherm are plotted against the $\alpha_{s}$ values, and this way, a new isotherm is obtained. This new isotherm is used to determine the primary mesopore volume, $V_{p}$, as follows: A straight line is drawn which passes through as many points as possible on the plateau region of the isotherm and the intercept of this line gives the total adsorbed gas volume in the primary mesopores per gram of the sample. The total adsorbed gas volume is converted into total adsorbed liquid volume by multiplying with a correction factor which is simply the ratio of the molar volume of liquid nitrogen at $77 \mathrm{~K}$ to the molar volume of nitrogen gas at STP assuming ideal gas behavior; that is, $34.65: 22,400 \mathrm{~cm}^{3} / \mathrm{g}$ [36]. This way, the total liquid nitrogen volume adsorbed in the primary mesopores $\left(V_{p}\right)$ is found. In our case, Li Chrospher Si-1000 Silica is chosen as the reference adsorbent for which the standard reduced nitrogen adsorption data (the $\alpha_{s}$ values) are well tabulated [37]. The adsorbed volume versus $\alpha_{s}$ graphs is plotted as seen in Figure 2 and a straight line is drawn to pass through as many points as possible on the linear/plateau regions of the isotherms. The intercepts of these lines are determined as shown on the plots and the $V_{p}$ values are estimated by converting the adsorbed gas volumes into adsorbed liquid volumes by multiplying with the abovementioned correction factor. The $V_{p}$ values thus determined are given in Table 1 and they are used in (2) to find the wall thickness, $\delta$, values also given in Table 1 . The $\delta$ values of the two purely siliceous samples, which depend on the degree of condensation of the silicate species during the synthesis procedure, are quite close to each other; thus, both of them will have similar thermal stabilities in different applications.

In summary, as seen from the XRD plots of the purely siliceous samples, the MCM-48-RTS sample has a better crystalline structure and a superior long range order than the MCM-HTS sample; this finding is supported by some literature studies which report that the room temperature synthesis yields better crystalline structures and more homogeneous particle shape distributions compared to the hydrothermal synthesis $[5,38]$.

3.1.2. Heteropoly-Acid-Incorporated Samples. In Figure 3, the XRD patterns of pure TPA preheated at 100 and $400^{\circ} \mathrm{C}$ are given. As seen in this figure, the characteristic peaks of the TPA form in the $2 \theta$ range of $10-50^{\circ}$ and some peak broadening is observed with increasing temperature 


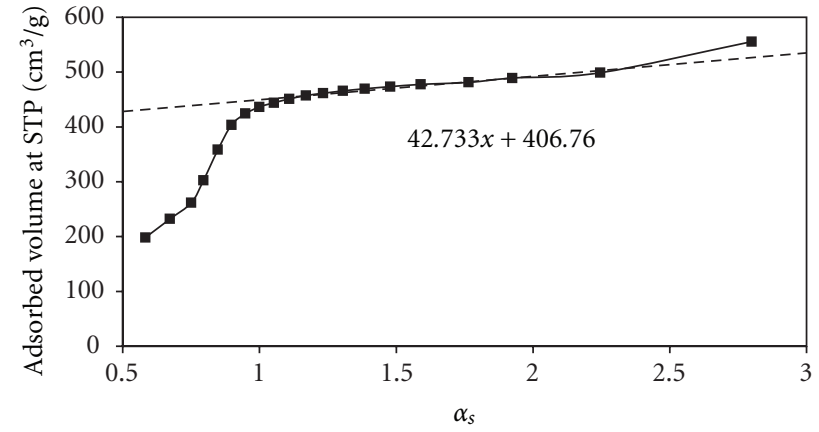

(a)

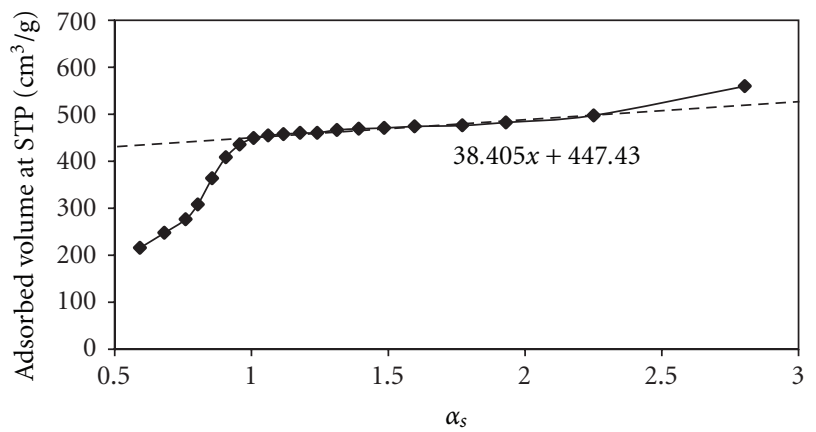

(b)

FIGURE 2: The $\alpha_{s}$ plots obtained from nitrogen adsorption isotherms measured on (a) MCM-48-HTS and (b) MCM-48-RTS.

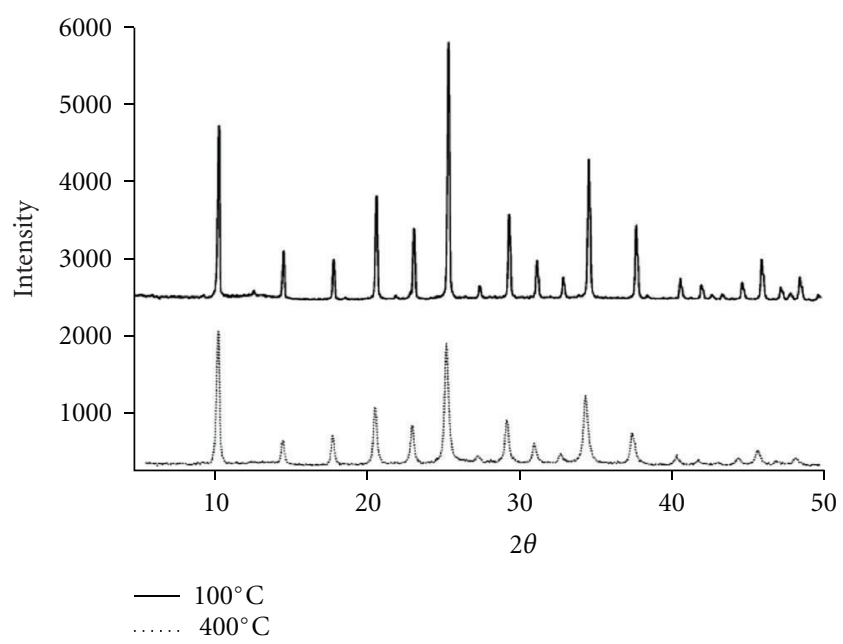

FIGURE 3: XRD patterns of pure TPA preheated at 100 and $400^{\circ} \mathrm{C}$ $[20]$.

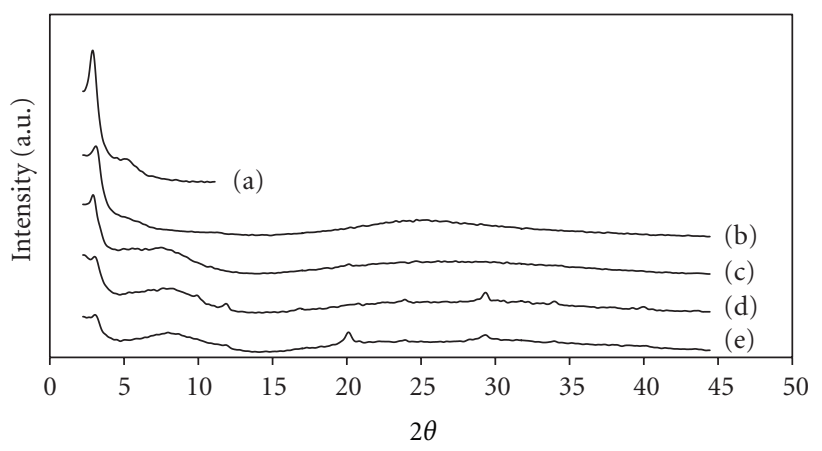

FIGURE 4: XRD patterns of the purely siliceous and HPA incorporated catalysts prepared by the HTS method: (a) MCM-48-HTS, (b) HTS-10\%, (c) HTS-20\%, (d) HTS-30\%, and (e) HTS- $40 \%$.

although the crystallinity is not significantly affected [20]. The XRD patterns of the HTS-X\% samples (hydrothermally synthesized samples with X wt $\%$ HPA incorporation) displayed in Figure 4 show a decreasing trend of peak

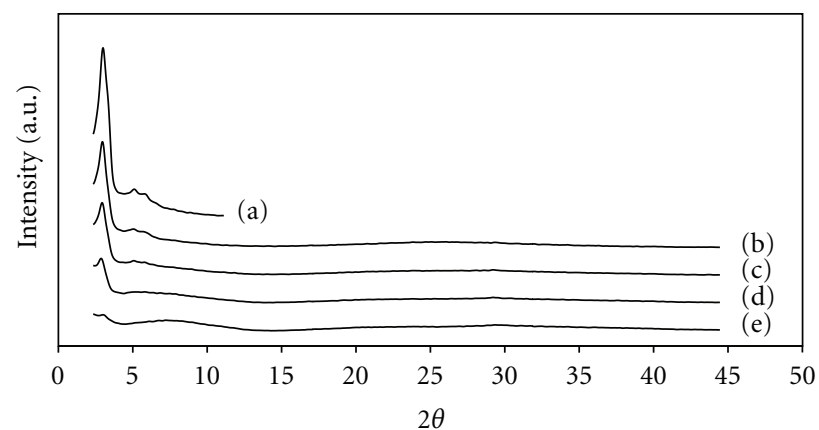

FIGURE 5: XRD patterns of the purely siliceous and HPA incorporated catalysts prepared by the RTS method: (a) MCM-48-RTS, (b) RTS-10\%, (c) RTS-20\%, (d) RTS-30\%, and (e) RTS-40\%.

intensity and an increasing trend of peak width with the increasing amount of HPA incorporation for the (211) peak. This is an expected result since the incorporation of acid deteriorates the structure and this effect is more pronounced as the amount of acid incorporated increases [9]. A diffraction band is obtained in the $2 \theta$ range of $15-$ $40^{\circ}$ for all HPA- incorporated HTS samples. This band indicates the presence of an amorphous region [39] formed due to HPA addition and the consequent deterioration in the structure. The small peaks observed on this band belong to TPA as can be inferred from Figure 3 and they indicate the presence of HPA crystals on the outer surfaces of the catalysts. On the other hand, the reductions in the pore diameters and the pore volumes, as seen in Table 2, indicate the presence of incorporated acid in the mesopores.

For the RTS-X\% samples (room temperature samples with $\mathrm{X} w \mathrm{t} \% \mathrm{HPA}$ incorporation), the XRD patterns given in Figure 5 are in general better than those corresponding to the HTS samples. This is due to the fact that the parent MCM-48-RTS has a better crystalline structure than the parent MCM-48-HTS and the incorporation of HPA does not deteriorate the catalyst structure significantly. In fact, the characteristic (211) peak and the additional (420) and (431) peaks are obtained with significant intensities for the RTS- $10 \%$ and RTS- $20 \%$ samples. For the RTS-30\% and RTS$40 \%$ samples, on the other hand, the characteristic (211) 
TABLE 3: EDS results of the HPA-incorporated catalysts.

\begin{tabular}{lccccc}
\hline Sample ID & W/Si (in solution) & W/Si (in solid) & Sample ID & W/Si (in solution) & W/Si (in solid) \\
\hline HTS-10\% & 0.0278 & 0.126 & RTS-10\% & 0.0278 & 0.135 \\
HTS-20\% & 0.0626 & 0.213 & RTS-20\% & 0.0626 & 0.248 \\
HTS-30\% & 0.1073 & 0.259 & RTS-30\% & 0.1073 & 0.275 \\
HTS-40\% & 0.1669 & 0.392 & RTS-40\% & 0.1669 & 0.356 \\
\hline
\end{tabular}

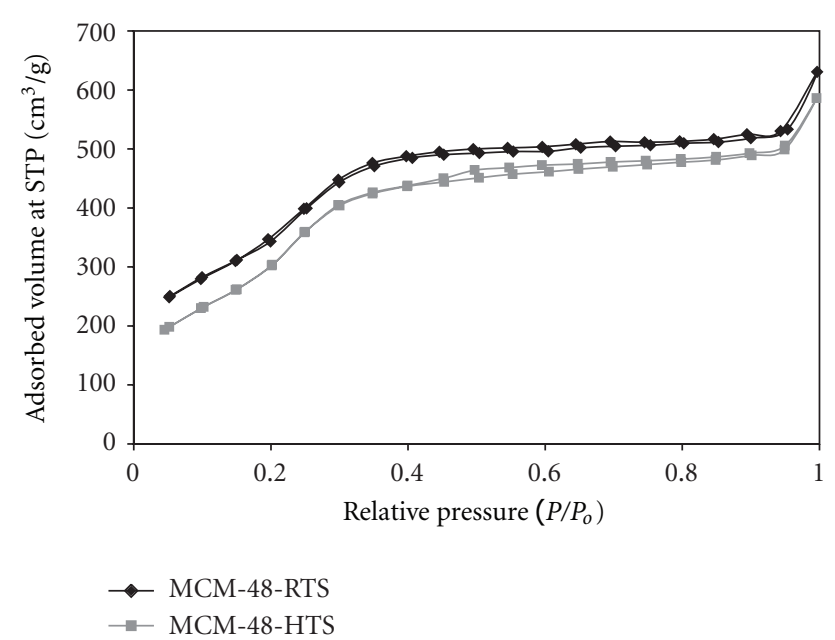

FIGURE 6: Nitrogen physisorption isotherms of the purely siliceous MCM-48-HTS and MCM-48-RTS catalysts.

peak broadens and its intensity decreases significantly with respect to the parent MCM-48 sample and the samples with lower amounts of acid incorporation. All samples also have the formation of the TPA peak around $26^{\circ}$ with very low intensities indicating some agglomeration of the TPA crystals on the catalyst surfaces [39].

The fact that the RTS samples have no significant peaks corresponding to TPA except for the small peaks around $26^{\circ}$ may indicate three situations: Only very low amounts of acid may have been incorporated into the structures, the acid may be well distributed in the mesopores, and/or the acid may be embedded in the amorphous silica walls so that the corresponding XRD peaks are not detectable. The EDS results given in Table 3 of Section 3.3 prove the incorporation of high amounts of TPA into the structure for all RTS samples as evidenced by the high W/Si molar ratios. In addition, the FT-IR results given in Figure 11 of Section 3.4 prove the incorporation of TPA with the Keggin structure into the RTS-40\% sample. Hence, the first situation is not possible. The BJH results given in Table 2 of Section 3.2.2 show that, for the RTS samples, the pore volumes decrease with increasing acid incorporation; however, the average pore diameter either remains constant or changes very slightly. Hence, it is concluded that there is some pore blockage due to the incorporation of acid into the mesopores; however, most of the incorporated acid is located in the amorphous silica walls.

\subsection{Nitrogen Physisorption Results}

3.2.1. Purely Siliceous Samples. The nitrogen physisorption isotherms of the purely siliceous samples MCM-48-HTS and MCM-48-RTS are given in Figure 6. It is seen that both catalysts have the Type IV isotherm of the IUPAC classification [40]. Both isotherms display hysteresis loops of Type H4 in the range of approximately $0.40<P / P \circ<0.95$ which indicate the presence of nonuniform slit-like pores [40-42] and secondary (larger) mesopores in the structure [43]. The HTS sample has a steep increase of adsorbed volume in the range of $0.95<P / P_{\circ}<1.00$ attributed to the macropores and spaces between the catalyst particles [44]. The macroporosity is observed with a lower degree for the RTS sample, too.

Investigation of Figure 7 shows that both catalysts have narrow pore size distributions centred at $2.2 \mathrm{~nm}$. In addition, the HTS sample also has three small peaks centred at 3.8, 4.8 , and $6.5 \mathrm{~nm}$ indicating the formation larger mesopores with these diameters. The RTS sample also has one small peak centred on $5.5 \mathrm{~nm}$ indicating the presence of secondary mesopores [43].

3.2.2. Heteropoly-Acid-Incorporated Samples. The nitrogen physisorption isotherms of the HPA-incorporated HTS and RTS samples are given in Figure 8. It is seen in Figure 8(a) that all HTS-X\% samples have the Type IV nitrogen physisorption isotherms with the H4 Type hysteresis loop which indicates that the samples are mesoporous with nonuniformly distributed, narrow, slit-like pores and secondary mesopores [40-43]. The most significant hysteresis effect is observed for the HTS-40\% catalyst due to the high amount of heteropoly acid incorporation and the resulting structure deterioration. Figure 8(b) shows that the RTS samples also display the characteristics of the Type IV physisorption isotherms; however, the hysteresis effects are less pronounced compared to the HTS samples. Hence, the RTS samples have more uniform pore geometries than the HTS samples. The most significant hysteresis effect is again obtained for the $40 \mathrm{wt} \%$ sample.

The results summarized in Table 2 support the findings of the nitrogen physisorption isotherms. As seen in this table, the RTS samples have higher surface areas than the HTS 


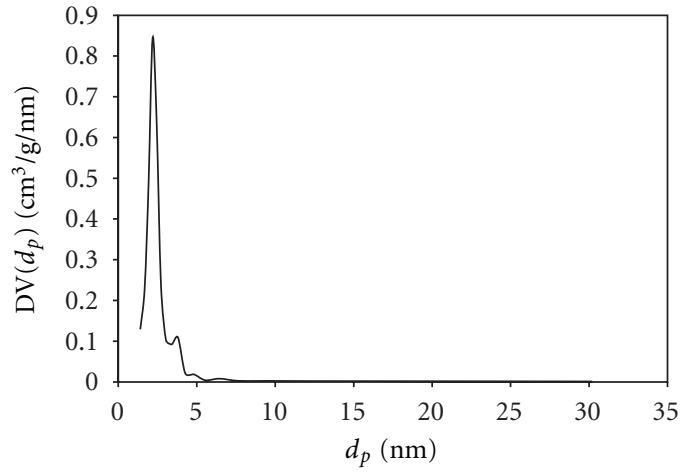

(a)

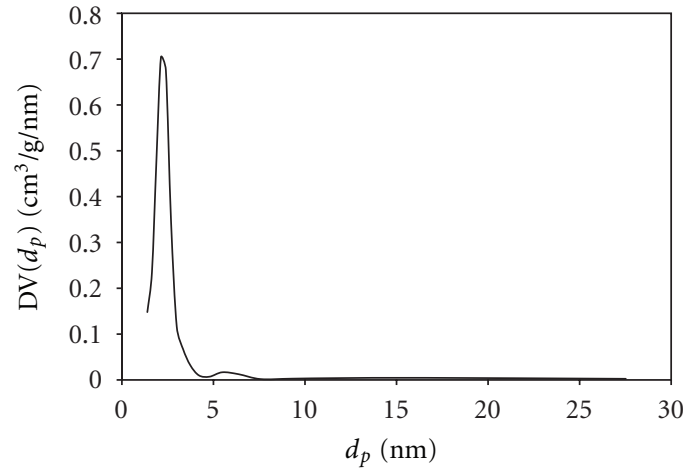

(b)

Figure 7: BJH pore size distributions of the purely siliceous catalysts (a) MCM-48-HTS and (b) MCM-48-RTS.

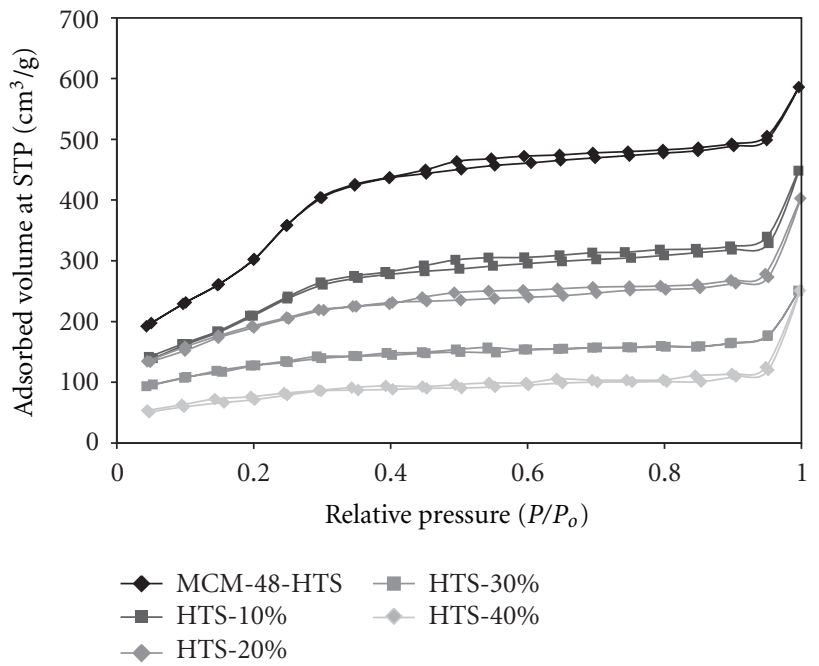

(a)

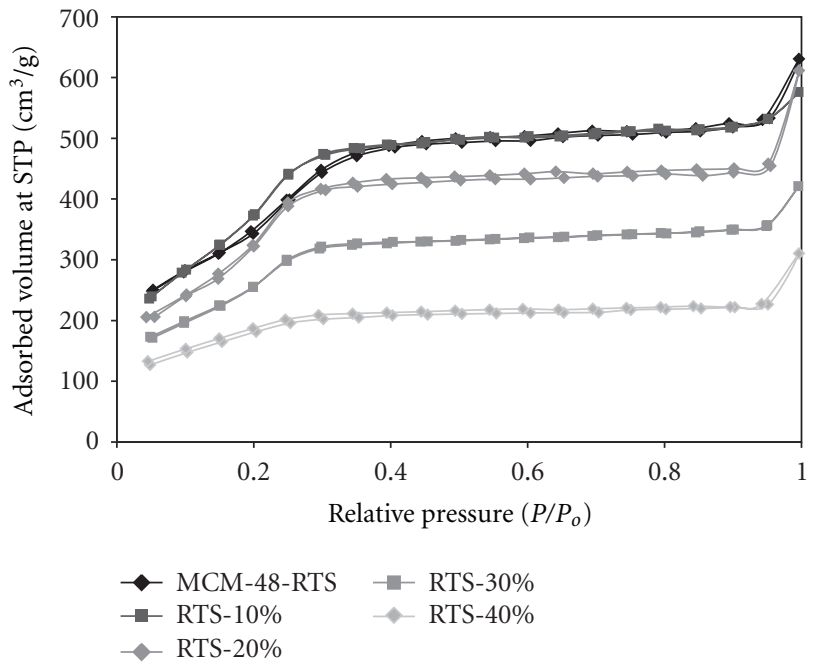

(b)

FIGURE 8: Nitrogen physisorption isotherms: (a) MCM-48-HTS catalysts and (b) MCM-48-RTS catalysts.

samples. The pore volumes corresponding to the RTS samples are also in general higher than those corresponding to the HTS samples. In terms of the average BJH desorption pore diameters, $d_{p}$, Table 2 depicts that, with the increasing incorporation of HPA, the pore diameters of the HTS samples decrease due to the pore blockage effects; that is, some part of the incorporated acid is dispersed in the pores. However, for the RTS samples, the pore diameters either remain constant or change very slightly with the addition of the HPA. This result and the absence of significant HPA peaks in the XRD patterns (Figure 5) imply that most of the incorporated acid is located in the amorphous silica walls of the RTS samples.

3.3. SEM, TEM, and EDS Results. SEM results of the purely siliceous and $40 \mathrm{wt} \%$ HPA-incorporated samples are given in Figure 9. This figure depicts that the MCM-48-RTS sample has a homogeneous distribution of spherical particles and the structure is not significantly affected upon acid addition although some agglomeration and particle shape deterioration is observed. MCM-48-HTS and HTS- $40 \%$ samples, however, have nonuniform lamellar structures and inhomogeneous particle shapes. TEM photographs of the purely siliceous samples given in Figure 10 show that some cubic mesophase formation is observed for both samples; however, the cubic pores are not homogeneously distributed. This situation may account for the low-intensity secondary peaks of the MCM-48-HTS sample, the broadening of the primary peak of the MCM-48-RTS sample, and the lack of the secondary characteristic (220) peaks for both samples in the XRD patterns.

The EDS results given in Table 3 show that although the W/Si molar ratios (in solid) are similar for both types of samples, the RTS samples have slightly higher addition of HPA compared to the HTS samples except for the $40 \mathrm{wt} \%$ acid incorporation. 


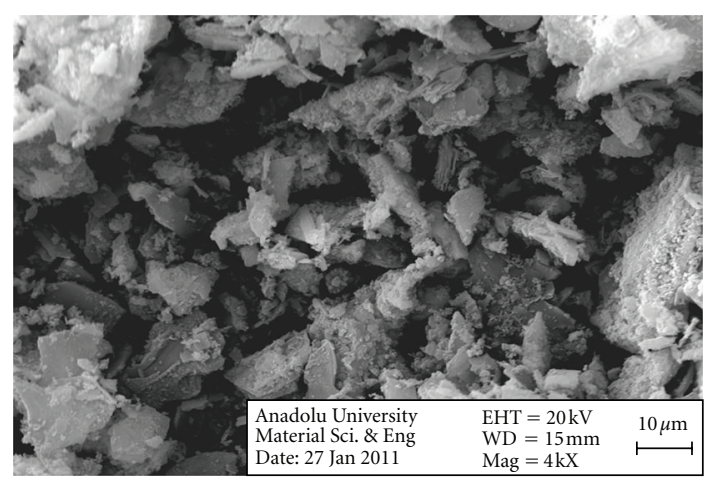

(a)

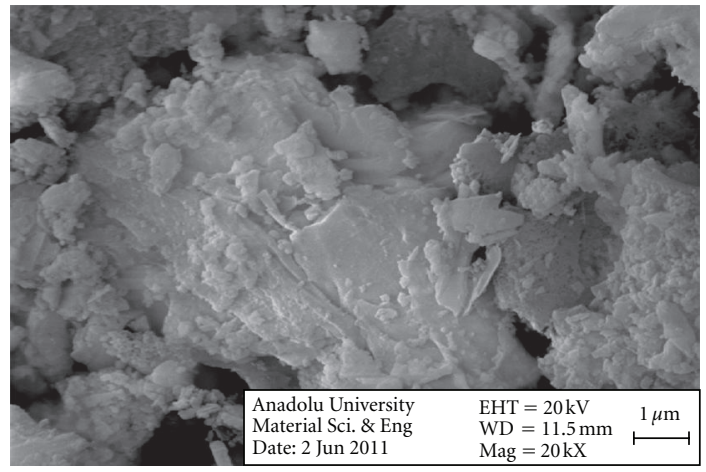

(c)

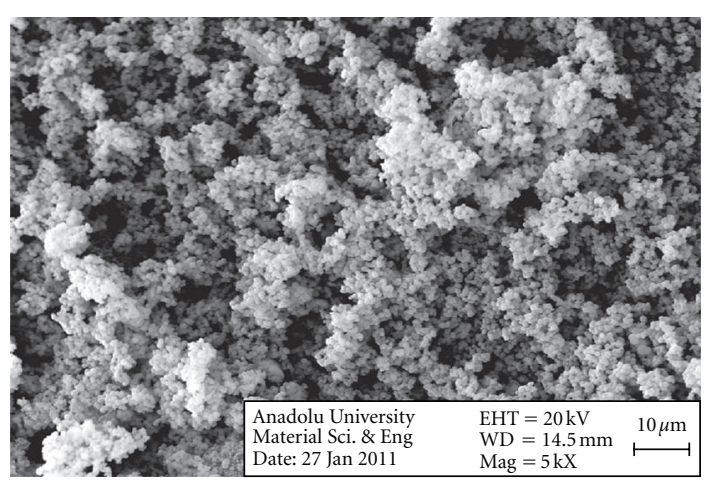

(b)

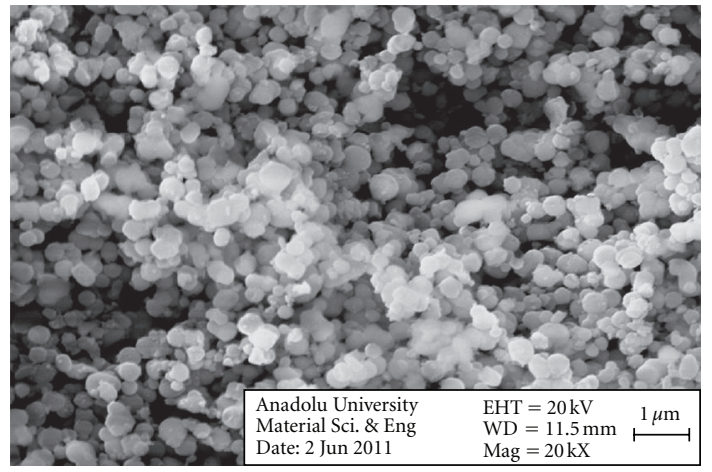

(d)

Figure 9: SEM photographs: (a) MCM-48-HTS, (b) MCM-48-RTS, (c) HTS-40\%, and (d) RTS-40\%.

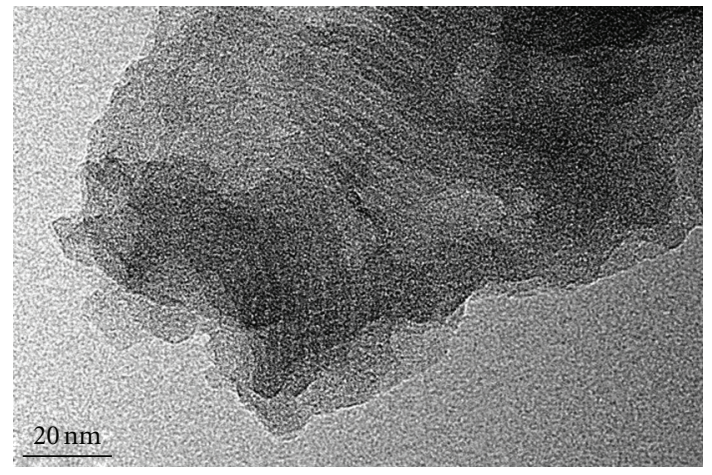

(a)

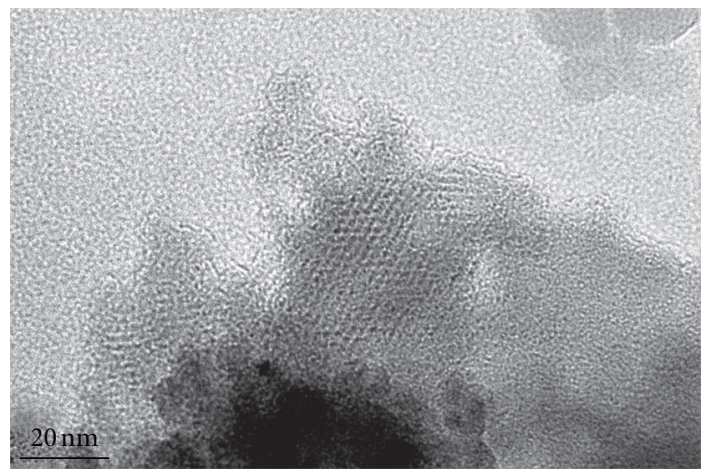

(b)

FIGURE 10: TEM photographs: (a) MCM-48-HTS and (b) MCM-48-RTS.

3.4. FT-IR Results. In Figure 11, the FT-IR spectra of the HTS-40\% and RTS-40\% samples are given along with the FT-IR spectrum of pure TPA. All the FT-IR spectra displayed in this figure, including the FT-IR spectra of the pure TPA, are found by subtracting the FT-IR spectra of the original catalyst from the FT-IR spectra of the pyridine-adsorbed catalyst. In this way, the peaks corresponding to the Keggin structure are clearly obtained; that is, pyridine is used as a probe molecule for the determination of the acidic sites [13].

It is known that the $\left(\mathrm{PW}_{12} \mathrm{O}_{40}\right)^{-3}$ Keggin ion found in the TPA structure consists of a central $\left(\mathrm{PO}_{4}\right)^{-3}$ tetrahedron which is surrounded by four threefold $\mathrm{W}_{3} \mathrm{O}_{13}$ units formed by each $\left(\mathrm{WO}_{6}\right)^{-6}$ octahedron sharing two edges with other $\left(\mathrm{WO}_{6}\right)^{-6}$ 's. The four $\mathrm{W}_{3} \mathrm{O}_{13}$ units are linked to one another by corner sharing $\mathrm{O}_{\text {corner }}$ atoms. The total assembly has a tetrahedral pocket in its center for the P heteroatom [45].

In Figure 11, the absorption bands observed at $807 \mathrm{~cm}^{-1}$ for pure TPA and HTS-40\% and at $805 \mathrm{~cm}^{-1}$ for RTS- $40 \%$ correspond to the stretching of the $\mathrm{W}-\mathrm{O}_{\text {edge }}-\mathrm{W}$ intrabridges between the edge-sharing $\left(\mathrm{WO}_{6}\right)^{-6}$ octahedra $[45,46]$. The bands observed in the range of $861-865 \mathrm{~cm}^{-1}$ for pure TPA and TPA-incorporated samples are also attributed to 


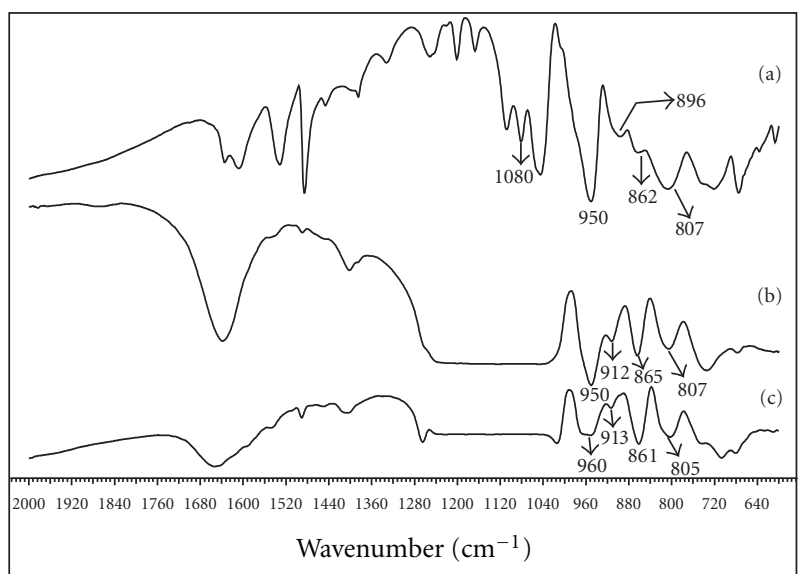

Figure 11: FT-IR spectra: (a) Pure TPA, (b) HTS-40\%, and (c) RTS$40 \%$.

the $\mathrm{W}-\mathrm{O}_{\text {edge }}-\mathrm{W}$ intrabridges [46]. The small peaks occurring at $896 \mathrm{~cm}^{-1}$ for pure TPA, at $912 \mathrm{~cm}^{-1}$ for HTS-40\%, and at $913 \mathrm{~cm}^{-1}$ for RTS- $40 \%$ correspond to the $\mathrm{W}-\mathrm{O}_{\text {corner }}-\mathrm{W}$ bond [20], and the absorption bands obtained around 950$960 \mathrm{~cm}^{-1}$ correspond to the vibrations of the $\mathrm{W}=\mathrm{O}_{\text {terminal }}$ functional group $[46,47]$ where $\mathrm{O}_{\text {terminal }}$ denotes a terminal oxygen atom connected to a lone tungsten atom [15]. Finally, broad absorption bands around $1120 \mathrm{~cm}^{-1}$ are obtained due to the overlapping of the stretching vibrations of the $\mathrm{P}-\mathrm{O}$ bonds of TPA $\left(1080 \mathrm{~cm}^{-1}\right)$ for the HTS-40\% and RTS-40\% catalysts [9].

\section{Conclusions}

In this work, MCM-48 type catalysts produced by the HTS and RTS synthesis methods were incorporated with tungstophosphoric acid in the range of $10-40 \mathrm{wt} \%$. The purely siliceous MCM-48-RTS catalyst, synthesized by the RTS method, was found to have a better crystalline structure and a higher BET surface area than the MCM-48-HTS catalyst synthesized by the HTS method. It also had a good structural morphology with well-defined spherical particles whereas the HTS catalyst had a nonuniform distribution of lamellar particles and random formation of some spherical particles. Due to these initial effects, TPA-incorporated RTS samples also had better crystalline structures, higher BET surface areas, and more homogeneous distribution of particle shapes compared to the HTS samples. TEM photographs illustrated the formation of some cubic mesophase for both samples; however, the cubic pores were not homogeneously distributed throughout the samples. The incorporation of TPA into both the HTS and RTS samples was proved by the EDS and FT-IR results. EDS results showed that the W/Si molar ratios (in solid) for both samples were only slightly different and somewhat higher acid incorporation was achieved for the RTS samples except for $40 \mathrm{wt} \%$ acid incorporation. FT-IR results, on the other hand, indicated that the Keggin ion structure was preserved even at the highest acid loadings of $40 \mathrm{wt} \%$ as evidenced by the peaks formed in the range of $800-1100 \mathrm{~cm}^{-1}$. Finally, it was seen that most of the acid incorporated into the HTS samples formed TPA clusters on the outer surfaces of the catalysts and the remaining acid was dispersed in the pores causing pore blockage and a consequent reduction in the BET surface areas, average pore diameters, and total pore volumes. TPA incorporated into the RTS samples, on the other hand, was mostly dispersed in the amorphous silica walls as evidenced by the XRD results and the average $d_{p}$ values. Hence, these catalysts had less reduction in BET surface areas and $\mathrm{BJH}$ pore volumes compared to the HTS samples and their average $\mathrm{BJH}$ pore diameters remained almost constant upon acid addition. As a summary, the RTS method, which is more economical and less time-consuming than the HTS method, was found to be more successful for the production of the HPA-MCM-48 type catalysts. The results of this study were presented as original findings since no prior comparative work exists in literature for HPA-MCM-48 type catalysts.

\section{References}

[1] C. T. Kresge, M. E. Leonowicz, W. J. Roth, J. C. Vartuli, and J. S. Beck, "Ordered mesoporous molecular sieves synthesized by a liquid-crystal template mechanism," Nature, vol. 359, no. 6397, pp. 710-712, 1992.

[2] J. S. Beck, J. C. Vartuli, W. J. Roth et al., "A new family of mesoporous molecular sieves prepared with liquid crystal templates," Journal of the American Chemical Society, vol. 114, no. 27, pp. 10834-10843, 1992.

[3] M. W. Anderson, "Simplified description of MCM-48," Zeolites, vol. 19, no. 4, pp. 220-227, 1997.

[4] J. Xu, Z. Luan, H. He, W. Zhou, and L. Kevan, "A reliable synthesis of cubic mesoporous MCM-48 molecular sieve," Chemistry of Materials, vol. 10, no. 11, pp. 3690-3698, 1998.

[5] K. Schumacher, M. Grün, and K. K. Unger, "Novel synthesis of spherical MCM-48," Microporous and Mesoporous Materials, vol. 27, no. 2-3, pp. 201-206, 1999.

[6] H. Li, S. Wang, F. Ling, and J. Li, "Studies on MCM48 supported cobalt catalyst for Fischer-Tropsch synthesis," Journal of Molecular Catalysis A, vol. 244, no. 1-2, pp. 33-40, 2006.

[7] D. Hua, S. Chen, G. Yuan, and Y. Wang, "Synthesis and characterization of tungsten-incorporated mesoporous molecular sieve MCM-48 by one step," Journal of Porous Materials, vol. 18, no. 6, pp. 729-734, 2010.

[8] M. Bandyopadhyay, N. R. Shiju, and D. R. Brown, "MCM-48 as a support for sulfonic acid catalysts," Catalysis Communications, vol. 11, no. 7, pp. 660-664, 2010.

[9] A. Sakthivel, K. Komura, and Y. Sugi, "MCM-48 supported tungstophosphoric acid: an efficient catalyst for the esterification of long-chain fatty acids and alcohols in supercritical carbon dioxide," Industrial and Engineering Chemistry Research, vol. 47, no. 8, pp. 2538-2544, 2008.

[10] Y. Gucbilmez, "Demir içerikli destekli ve desteksiz katalizör sentezi ve karakterizasyonu," Journal of the Faculty of Engineering and Architecture of Gazi University, vol. 24, no. 2, pp. 369377, 2009.

[11] I. V. Kozhevnikov, "Heteropoly acids and related compounds as catalysts for fine chemical synthesis," Catalysis Reviews, vol. 37, no. 2, pp. 311-352, 1995. 
[12] I. V. Kozhevnikov, K. R. Kloetstra, A. Sinnema, H. W. Zandbergen, and H. Van Bekkum, "Study of catalysts comprising heteropoly acid $\mathrm{H}_{3} \mathrm{PW}_{12} \mathrm{O}_{40}$ supported on MCM-41 molecular sieve and amorphous silica," Journal of Molecular Catalysis A, vol. 114, no. 1-3, pp. 287-298, 1996.

[13] Y. Li, W. Chu, M. Chen, and J. Hu, "Preparation of the supported heteropolyacids catalyst by ultrasound-plasma treatment," Journal of Wuhan University of Technology, Materials Science Edition, vol. 23, no. 2, pp. 234-238, 2008.

[14] V. S. Nayak and J. B. Moffat, "Sorption and diffusion of alcohols in heteropoly oxometalates and ZSM-5 zeolite," Journal of Physical Chemistry, vol. 92, no. 25, pp. 7097-7102, 1988.

[15] Y. Zhang and S. Yang, "Synthesis, characterization and catalytic application of $\mathrm{H}_{3} \mathrm{PW}_{12} \mathrm{O}_{40} / \mathrm{MCM}-48$ in the esterification of methacrylic acid with n-butyl alcohol," Journal of Wuhan University of Technology, Materials Science Edition, vol. 23, no. 3, pp. 346-349, 2008.

[16] Q. Wu, H. Jin, W. Feng, and W. Pang, "Preparation and conductivity of decatungstomolybdovanado-germanic heteropoly acid supported on mesoporous silica SBA-15, SBA-16, MCM41 and MCM-48," in Studies in Surface Science and Catalysis, D. Zhao, S. Qiu, Y. Tang, and C. Yu, Eds., vol. 165, pp. 847-851, Elsevier Science B.V., 2007.

[17] M. Bhagiyalakshmi, P. Hemalatha, M. Ganesh, M. M. Peng, and H. T. Jang, "Synthesis of copper exchanged heteropolyacids supported on MCM-48 and its application for $\mathrm{CO}_{2}$ adsorption," Journal of Industrial and Engineering Chemistry, vol. 17, no. 3, pp. 628-632, 2011.

[18] A. Bordoloi, F. Lefebvre, and S. B. Halligudi, "Selective oxidation of anthracene using inorganic-organic hybrid materials based on molybdovanadophosphoric acids," Journal of Catalysis, vol. 247, no. 2, pp. 166-175, 2007.

[19] M. Gómez-Ruiz, J. A. Melo Banda, C. E. Ramos-Galván et al., "Alkylation of benzene with propylene over $\mathrm{H}_{3} \mathrm{PW}_{12} \mathrm{O}_{40}$ supported on MCM-41 and -48 type mesoporous materials," Advanced Materials Research, vol. 132, pp. 195-204, 2010.

[20] P. A. Jalil, M. Faiz, N. Tabet, N. M. Hamdan, and Z. Hussain, "A study of the stability of tungstophosphoric acid, $\mathrm{H}_{3} \mathrm{PW}_{12} \mathrm{O}_{40}$, using synchrotron XPS, XANES, hexane cracking, XRD, and IR spectroscopy," Journal of Catalysis, vol. 217, no. 2, pp. 292-297, 2003.

[21] W. Lin, Q. Cai, W. Pang, Y. Yue, and B. Zou, "New mineralization agents for the synthesis of MCM-41," Microporous and Mesoporous Materials, vol. 33, no. 1-3, pp. 187-196, 1999.

[22] L. Pei, K. I. Kurumada, M. Tanigaki, M. Hiro, and K. Susa, "Effect of drying rate on mesoporous silica morphology templated from PEO-PPO-PEO block copolymer assemblies," Journal of Materials Science, vol. 39, no. 12, pp. 4045-4047, 2004.

[23] A. S. Araujo and M. Jaroniec, "Thermogravimetric monitoring of the MCM-41 synthesis," Thermochimica Acta, vol. 363, no. 1-2, pp. 175-180, 2000.

[24] W. Thitsartarn, E. Gulari, and S. Wongkasemjit, "Synthesis of Fe-MCM-41 from silatrane and $\mathrm{FeCl}_{3}$ via sol-gel process and its epoxidation acivity," Applied Organometallic Chemistry, vol. 22, no. 2, pp. 97-103, 2008.

[25] G. Zhang, L. Tao, and G. Zhang, "MCM-41 prepared with ionic liquid and cethytrimethylammonium bromide as cotemplates," Journal of Wuhan University of Technology, Materials Science Edition, vol. 24, pp. 25-29, 2009.

[26] M. Bandyopadhyay, Synthesis of mesoporous MCM-48 with nanodispersed metal and metal oxide particles inside the pore system, Doctoral Thesis, Ruhr-Universität, Bochum, Germany, 2004.
[27] H. Ju Park, J. H. Yim, J. K. Jeon, J. Man Kim, K. S. Yoo, and Y. K. Park, "Pyrolysis of polypropylene over mesoporous MCM48 material," Journal of Physics and Chemistry of Solids, vol. 69, no. 5-6, pp. 1125-1128, 2008.

[28] M. Kruk, M. Jaroniec, R. Ryoo, and S. H. Joo, "Characterization of ordered mesoporous carbons synthesized using MCM48 silicas as templates," Journal of Physical Chemistry B, vol. 104, no. 33, pp. 7960-7968, 2000.

[29] P. I. Ravikovitch and A. V. Neimark, "Relations between structural parameters and adsorption characterization of templated nanoporous materials with cubic symmetry," Langmuir, vol. 16, no. 6, pp. 2419-2423, 2000.

[30] G. A. Eimer, L. B. Pierella, G. A. Monti, and O. A. Anunziata, "Synthesis and characterization of Al-MCM-41 and Al-MCM48 mesoporous materials," Catalysis Letters, vol. 78, no. 1-4, pp. 65-75, 2002.

[31] J. Choma, M. Kloske, M. Jaroniec, and J. Klinik, "Benzene adsorption isotherms on MCM-41 and their use for pore size analysis," Adsorption, vol. 10, no. 3, pp. 195-203, 2004.

[32] P. Prokešová-Fojtíková, S. Mintova, J. Čejka, N. Žilková, and A. Zukal, "Porosity of micro/mesoporous composites," Microporous and Mesoporous Materials, vol. 92, no. 1-3, pp. 154-160, 2006.

[33] J. Sun and M.-O. Coppens, "Alcothermal synthesis of large pore high quality MCM-38 silica," in Studies in Surface Science and Catalysis, A. Sayari and M. Jaroniec, Eds., vol. 141, pp. 8592, Elsevier Science B.V., 2002.

[34] M. Bandyopadhyay and H. Gies, "Synthesis of MCM-48 by microwave-hydrothermal process," Comptes Rendus Chimie, vol. 8, no. 3-4, pp. 621-626, 2005.

[35] Y. Shao, L. Wang, J. Zhang, and M. Anpo, "Novel synthesis of high hydrothermal stability and long-range order MCM48 with a convenient method," Microporous and Mesoporous Materials, vol. 86, no. 1-3, pp. 314-322, 2005.

[36] M. Önal, Y. Sarikaya, and T. Alemdaroğlu, "Investigation of the microporous and mesoporous structures of the ręadiye (Tokat/Turkey) bentonite and its fractions," Turkish Journal of Chemistry, vol. 25, no. 2, pp. 241-249, 2001.

[37] M. Jaroniec, M. Kruk, and J. P. Olivier, "Standard nitrogen adsorption data for characterization of nanoporous silicas," Langmuir, vol. 15, no. 16, pp. 5410-5413, 1999.

[38] K. Schumacher, P. I. Ravikovitch, A. Du Chesne, A. V. Neimark, and K. K. Unger, "Characterization of MCM-48 materials," Langmuir, vol. 16, no. 10, pp. 4648-4654, 2000.

[39] G. Kamalakar, K. Komura, Y. Kubota, and Y. Sugi, "FriedelCrafts benzylation of aromatics with benzyl alcohols catalyzed by heteropoly acids supported on mesoporous silica," Journal of Chemical Technology and Biotechnology, vol. 81, no. 6, pp. 981-988, 2006.

[40] K. S. W. Sing, D. H. Everett, R. A. W. Haul et al., "Reporting physisorption data for gas/solid systems with special reference to the determination of surface area and porosity," Pure and Applied Chemistry, vol. 57, no. 4, pp. 603-619, 1985.

[41] M. Kruk and M. Jaroniec, "Gas adsorption characterization of ordered organic-inorganic nanocomposite materials," Chemistry of Materials, vol. 13, no. 10, pp. 3169-3183, 2001.

[42] R. J. Hunter, Foundations of Colloid Science, Oxford University Press, Oxford, UK, 2nd edition, 2001.

[43] S. J. Gregg and K. S. W. Sing, Adsorption, Surface Area and Porosity, Elsevier/Academic Press, London, UK, 2nd edition, 1982.

[44] S. Lim, D. Ciuparu, Y. Yang, G. Du, L. D. Pfefferle, and G. L. Haller, "Improved synthesis of highly ordered Co-MCM-41," 
Microporous and Mesoporous Materials, vol. 101, no. 1-2, pp. 200-206, 2007.

[45] G. Ranga Rao and T. Rajkumar, "Investigation of 12-tungstophosphoric acid supported on $\mathrm{Ce}_{0.5} \mathrm{Zr}_{0.5} \mathrm{O}_{2}$ solid solution," Catalysis Letters, vol. 120, no. 3-4, pp. 261-273, 2008.

[46] R. Sumathi, D. Sengupta, and M. T. Nguyen, "Theoretical study of the $\mathrm{H}_{2}+\mathrm{NO}$ and related reactions of $\left[\mathrm{H}_{2} \mathrm{NO}\right]$ isomers," Journal of Physical Chemistry A, vol. 102, no. 18, pp. 3175-3183, 1998.

[47] A. V. Ivanov, T. V. Vasina, V. D. Nissenbaum, L. M. Kustov, M. N. Timofeeva, and J. I. Houzvicka, "Isomerization of n-hexane on the Pt-promoted Keggin and Dawson tungstophosphoric heteropoly acids supported on zirconia," Applied Catalysis A, vol. 259, no. 1, pp. 65-72, 2004. 

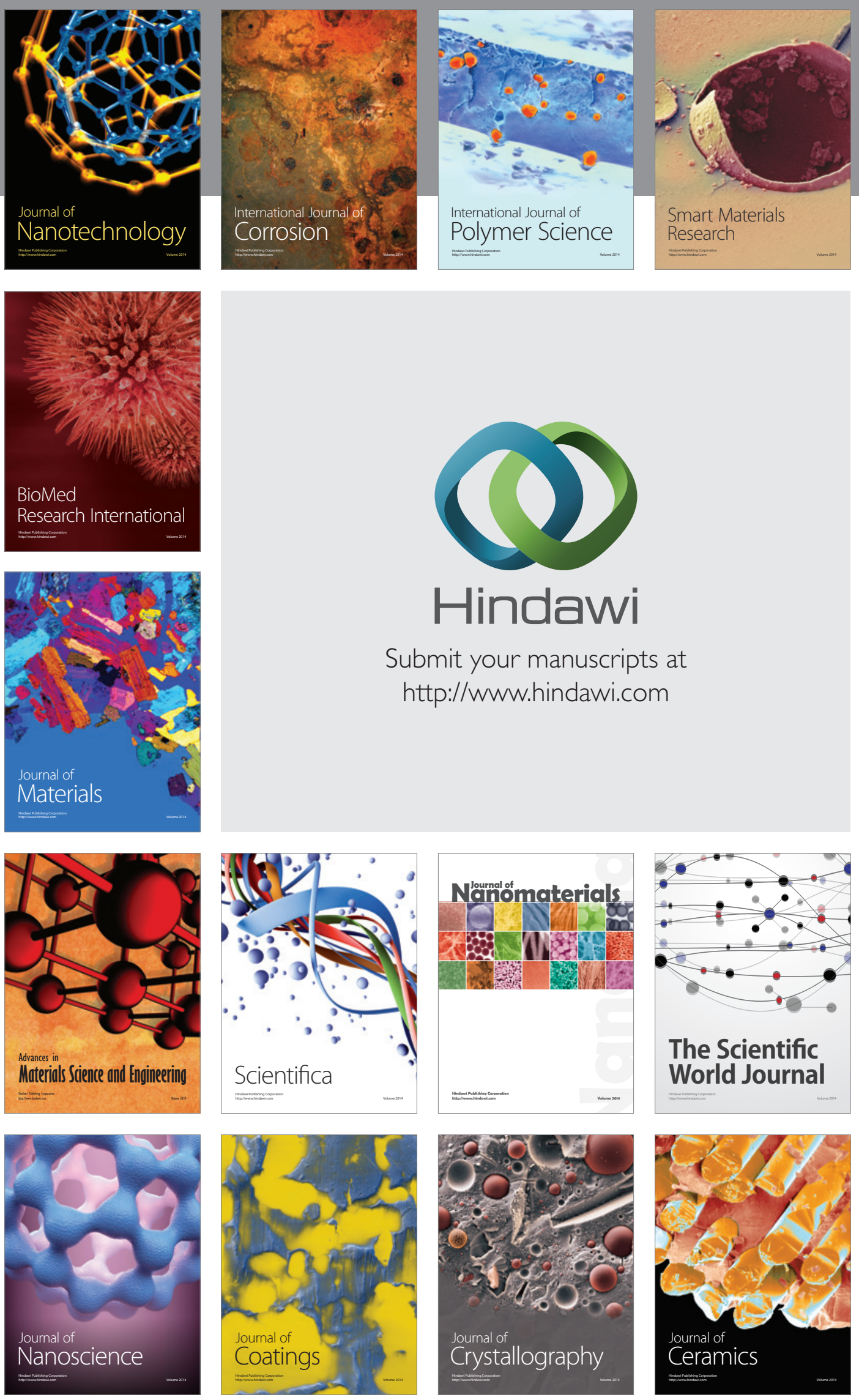

The Scientific World Journal

Submit your manuscripts at

http://www.hindawi.com

\section{World Journal}

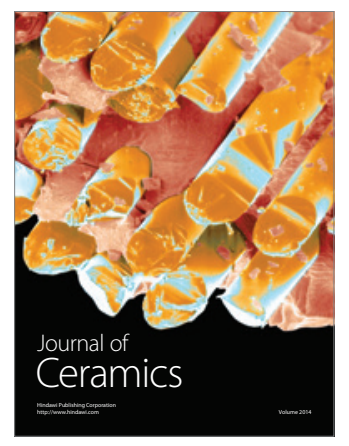

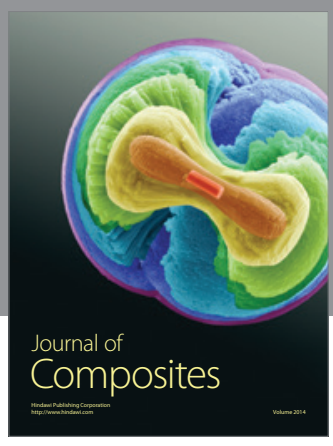
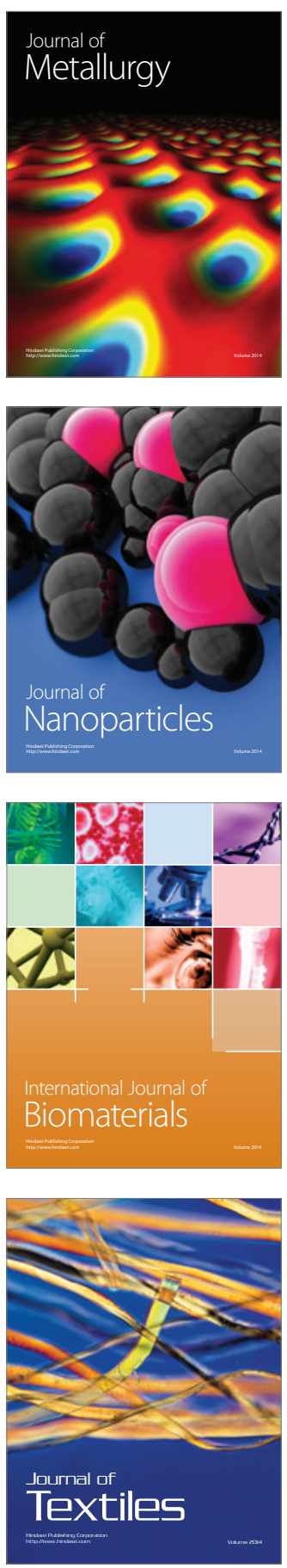